\title{
PLANOS DIRETORES DE ARBORIZAÇÃO URBANA: NECESSIDADE DE INCORPORAÇÃO NA LEGISLAÇÃO BRASILEIRA
}

\author{
URBAN FOREST MASTER PLANS: NEED TO INCORPORATE IN BRAZILIAN \\ LEGISLATION
}

\author{
Cássia Conceição da Cruz Nespolo', Emanoele Lima Abreu², Caroline Pardi Vicente”, \\ Renata Bovo Peres ${ }^{4}$
}

\section{RESUMO}

A Arborização Urbana torna-se um elemento fundamental no planejamento urbano, devido aos seus serviços ecossistêmicos, porém, é necessária a criação de legislação para possibilitar sua devida implantação. O objetivo deste trabalho foi a realização de levantamento bibliográfico e documental que visou, dentro da legislação federal, estadual e municipal, identificar a existência de leis sobre Arborização Urbana ou Planos Diretores de Arborização Urbana - PDAUs, com o propósito de verificar o panorama geral dessa temática na legislação brasileira. Foi utilizada uma abordagem qualitativa, própria para quem busca entender fenômenos específicos e complexos, em profundidade, por meio de descrições, comparações e interpretações. Os resultados mostraram que, mesmo com a deficiência de leis federais, alguns estados e municípios têm tomado a iniciativa de incorporar a arborização urbana em suas leis ou outros instrumentos de planejamento como programas, projetos, manuais, etc. A incorporação do Plano Diretor de Arborização Urbana - PDAU na legislação brasileira conduziria a uma maior padronização na aplicação de políticas públicas de Arborização Urbana nos municípios e garantiria o direito às cidades sustentáveis previsto no Estatuto da Cidade - Lei Federal n 10.257/2001.

Palavras-chave: Planos de arborização; Árvores urbanas; Leis; Regulação.

\begin{abstract}
Afforestation becomes a fundamental element in urban planning, due to its ecosystem services, however, it is necessary to create legislation to enable its proper implementation. The objective of this study was to carry out a bibliographic and documentary survey that aimed, within the federal, state and municipal legislation, to identify the afforestation laws or the Urban Forest Master Plan - UFMP, in order to verify the general panorama of this theme in Brazilian legislation. A qualitative approach was used, proper for those who seek to understand changes and complexities, in depth, through descriptions, comparisons and interpretations. The results showed that, even with deficiency in federal laws, some states and municipalities have the initiative to incorporate afforestation in their laws or other planning instruments such as programs, projects, manuals, etc. The incorporation of the Urban Forest Master Plan - UFMP, in Brazilian legislation, would lead to a greater standardization in the application of public Arboriculture policies in the municipalities and guarantee the right to sustainable cities provided for in the City Statute - Federal Law $n^{\circ}$ 10,257 / 2001.
\end{abstract}

Keywords: Arboriculture plans; Urban trees; Laws; Regulation.

Recebido em 01.12.2019 e aceito em 07.05.2020

1 Mestranda em Ciências Ambientais. Universidade Federal de São Carlos, campus São Carlos/SP. Email: cassianespolo@gmail.com

2 Doutoranda em Ciências Ambientais. Universidade Federal de São Carlos, campus São Carlos/SP. Email: emanoelelimaabreu@gmail.com

3 Mestranda em Ciências Ambientais. Universidade Federal de São Carlos, campus São Carlos/SP. E-mail: carol.pardi2@gmail.com

4 Doutora em Engenharia Urbana. Professora Adjunta no Departamento de Ciências Ambientais da Universidade Federal de São Carlos, campus São Carlos/SP. Email: renataperes@ufscar.br 


\section{INTRODUÇÃO}

As árvores urbanas desempenham diversas funções que trazem uma vasta gama de benefícios para as cidades. Dentre elas estão: reduzir o impacto das águas pluviais; prover sombra; propiciar a conectividade da paisagem e habitat para a fauna; melhorar a qualidade do ar; proporcionar a interação entre comunidades; valorizar as propriedades; etc. (MULLANEY; LUCKE; TRUEMAN, 2015). No caso de cidades de clima mais quente, para que o resfriamento seja mais eficaz, as árvores devem ser distribuídas em toda a paisagem. O sombreamento das copas das árvores pode diminuir o nível de estresse causado pelo calor durante o dia, principalmente se colocadas estrategicamente onde os pedestres provavelmente estarão expostos a altos níveis de radiação solar (COUTTS et al., 2016).

Com a perda da vegetação, principalmente nativa, perdem-se inúmeras funções ecológicas no ambiente, o que pode comprometer ainda mais a manutenção dos serviços ambientais, tais como: proteção do solo, polinização de cultivos agrícolas, purificação da água e regulação do clima (BRANCALION et al., 2016). Conforme Kramer e Krupek (2016), as árvores em meio urbano têm benefícios ecológicos significativos, pois podem contribuir com a preservação ecológica local e conservação de espécies endêmicas.

Ahern (2011) menciona que, no novo mundo urbano, planejadores e designers serão desafiados a alcançar novas formas de fornecimento de serviços ecossistêmicos sustentáveis nas cidades que têm espaços cada vez mais limitados e compactos. Nessa perspectiva, a Arborização Urbana vem sendo considerada uma temática fundamental a ser incorporada no planejamento urbano, pois seus serviços ecossistêmicos podem contribuir com as futuras gerações e melhorar a qualidade de vida da população, além de evitar o aumento de problemas ao meio ambiente. Para isso, a criação de legislação e de diretrizes especificas podem possibilitar sua devida implantação.

O estabelecimento de diretrizes, buscando conciliar as árvores com os diversos usos do solo urbano, auxilia e norteia o planejamento da arborização. O crescimento das cidades induz ao parcelamento do solo, permitindo ao mercado imobiliário, a inserção de terras urbanas, além disso, no solo estão incluídos os espaços livres destinados às áreas verdes públicas (BENINI; MARTIN, 2010). Esse fato reforça a necessidade de diretrizes, que podem ser enquadradas no Plano Diretor de cada cidade, muito embora este seja obrigatório apenas para um conjunto de cidades, de acordo com o art. 41 do Estatuto da Cidade - EC, sancionado pela Lei Federal ํo 10.257/2001 (BRASIL, 2001).

No art. 4 do EC, dentre os instrumentos da Política Urbana propostos, estão o Plano Diretor e; os planos, programas e projetos setoriais (BRASIL, 2001). Não há uma citação específica nem a obrigatoriedade do planejamento da Arborização Urbana, porém, esse 
elemento faz parte das áreas verdes e pode ser incluído nas delimitações de parcelamento do solo constantes nesses planos setoriais.

A produção de efeitos positivos e benéficos trazidos pela arborização requer a aplicação de um manejo adequado da arborização de ruas, cuidando da manutenção das árvores nas vias públicas e contribuindo com a comunidade, o que consiste no desenvolvimento de um Plano Diretor de Arborização Urbana - PDAU que possibilite a seleção e o plantio de árvores, direcionando a manutenção dessas árvores e a sua substituição quando necessário (SCHALLENBERGER; MACHADO, 2013).

Em nível federal não existe no Brasil uma Política Nacional de Arborização Urbana, ainda que este movimento esteja sendo defendido em Congressos e Redes sobre a temática (CAICHE; PERES, 2019). O que se pode observar, até agora, é que alguns municípios incorporam a Arborização Urbana em seus Planos Diretores, e outros municípios elaboram Planos Diretores de Arborização Urbana ou leis ambientais municipais que determinam algumas diretrizes e medidas mais específicas.

A exigência para a elaboração de PDAUs na legislação brasileira, principalmente em nível federal, poderia representar um avanço, tendo em vista a carência de instrumentos capazes de orientar e regulamentar a sua incorporação na gestão urbana e ambiental, dando suporte legal aos estados e municípios brasileiros.

Justifica-se, portanto, este trabalho pela necessidade de compreender melhor sobre essa questão no país, envolvendo estudos sobre as legislações existentes, sobre os Planos Diretores de Arborização Urbana já elaborados em algumas cidades, até formas de regulamentação e implementação de alguns instrumentos.

O objetivo deste trabalho foi a realização de levantamento bibliográfico e documental que visou, dentro da legislação federal, estadual e municipal, identificar a existência de leis sobre Arborização Urbana ou Planos Diretores de Arborização Urbana - PDAUs, com o propósito de verificar o panorama geral dessa temática na legislação brasileira.

\section{MATERIAL E MÉTODOS}

O presente trabalho utilizou uma abordagem qualitativa que, segundo Andrade e Holanda (2010), não corresponde apenas a uma definição instrumental, mas sim, teórica e epistemológica, ou seja, é um tipo de abordagem que trata de fenômenos que se relacionam com o conhecimento, sua natureza e suas limitações.

Foram realizadas pesquisas bibliográfica e documental buscando levantar dados sobre Arborização Urbana e Planos Diretores de Arborização Urbana na legislação federal, estadual e 
municipal brasileiras. Ambas utilizaram os strings de busca "arborização", "arborização urbana", "árvore" e "plano", no intuito de identificar a base legal relacionada ao tema.

A pesquisa bibliográfica foi feita mediante revisão da literatura, por meio de busca em artigos, livros, teses e dissertações, nas bases de dados: BDTD (Biblioteca Digital Brasileira de Teses e Dissertações), Portal de Periódicos CAPES/MEC, Scientific Electronic Library Online (Scielo), Scopus (Elsevier), Science Direct (Elsevier), Web of Science e Directory of Open Access Journals (DOAJ). A pesquisa documental foi feita: no Diário Oficial da União, a nível federal; nos websites dos órgãos estaduais ambientais e no Diário Oficial dos respectivos estados, a nível estadual; e nos websites de Leis Municipais e do Instituto Brasileiro de Geografia e Estatística IBGE, a nível municipal.

Por se tratar de um tema ainda recente na literatura nacional e com gradativa adesão nas políticas públicas ambientais e urbanas, não houve recorte temporal. Dessa forma, todas as iniciativas a nível federal e estadual foram levantadas. A nível municipal, todavia, o mesmo não ocorreu. A ausência de informações dos municípios brasileiros em bases de dados nacional como, por exemplo, no IBGE dificulta o levantamento desse tema a nível local.

\section{RESULTADOS E DISCUSSÃO}

\section{Arborização urbana na legislação federal}

No âmbito nacional, existem algumas leis fundamentais relacionadas às questões ambientais e do parcelamento do solo urbano que delimitam ações referentes ao meio ambiente e ordenamento do território. A despeito dessas importantes normativas, nenhuma delas tratou e incorporou a temática da Arborização Urbana como um tema estruturante.

Promulgada em 1979, a Lei Federal n 6.766/1979 - lei do parcelamento do solo (BRASIL, 1979), trata dos requisitos urbanísticos mínimos, da elaboração e aprovação de projetos, dos registros, contratos e regulamenta toda a ação permitida por lei em relação aos loteamentos e desmembramentos do solo urbano. No Art. 6, essa lei requisita que, nos casos de projeto de loteamento, antes da elaboração, o interessado solicite à Prefeitura Municipal ou ao Distrito Federal, quando necessário, a definição das "diretrizes para o uso do solo, traçado dos lotes, do sistema viário, dos espaços livres e das áreas reservadas para equipamento urbano e comunitário (...)" (BRASIL, 1979).

A Lei nacional de meio ambiente, $n^{\circ}$ 6.938/1981, "dispõe sobre a Política Nacional do Meio Ambiente, seus fins e mecanismos de formulação e aplicação, e dá outras providências" (BRASIL, 1981). Essa lei traz definições significantes a respeito do meio ambiente e de sua 
necessidade de preservação, melhoria e recuperação, sendo ele fundamental na manutenção do equilíbrio ecológico e considerado "um patrimônio público a ser necessariamente assegurado e protegido, tendo em vista o uso coletivo" (BRASIL, 1981). A Política Nacional do Meio Ambiente define o meio ambiente natural como um patrimônio público a ser assegurado, protegido e recuperado (BRASIL, 1981).

Dentro das questões ambientais, a Constituição Federal de 1988 (CF/88), que embasa toda a legislação brasileira, no Art. 23, compete à União, aos Estados, ao Distrito federal e aos Municípios, a proteção do meio ambiente e combate à poluição em qualquer de suas formas (inc. VI); e a preservação das florestas, da fauna e da flora (inc. VII) (BRASIL, 1988).

Ainda na CF/88 os Arts. 182 e 183 estabelecem diretrizes gerais da Política Urbana, no qual atribuem ao Poder Público Municipal a responsabilidade pelo "pleno desenvolvimento das funções sociais da cidade e garantir o bem-estar de seus habitantes" e a obrigatoriedade de um Plano Diretor para cidades com mais de 20 mil habitantes (BRASIL, 1988). No Art. 30, inc. VIII é delegada aos municípios a competência de "promover, no que couber, adequado ordenamento territorial, mediante planejamento e controle do uso, do parcelamento e da ocupação do solo urbano", um papel fundamental do Plano Diretor (BRASIL, 1988).

Mesmo com a obrigatoriedade já prevista na CF de 1988, foi em 2001, com a Lei Federal $n^{\circ} 10.257$ - Estatuto da Cidade (EC), que foi estipulado um prazo de cinco anos para que os municípios instituíssem seus Planos Diretores, além de definir que sua revisão deveria ocorrer, pelo menos, a cada dez anos, (BRASIL, 2001), dando maior autonomia para os municípios e suas particularidades ambientais. No Art. $2^{\circ}$ (funções sociais da cidade e da propriedade urbana) dessa lei, um conjunto de cidades passou a ter a obrigatoriedade de elaborar um Plano Diretor que deve assegurar $\mathrm{o}$ atendimento das necessidades dos cidadãos quanto à qualidade de vida, à justiça social e ao desenvolvimento das atividades econômicas, respeitadas as diretrizes previstas (BRASIL, 2001).

O Plano Diretor é o instrumento primordial para o ordenamento do uso do solo municipal, sendo um documento legal base para os gestores públicos, transferindo os instrumentos do Estatuto da Cidade para o território dos municípios (BERNARDY, 2013).

Em nível federal, a legislação relacionada diretamente com a Arborização Urbana ainda não passa de alguns Projetos de Lei - PLs que fizeram propostas para alterar o Estatuto da Cidade - EC na tentativa de incorporar nele a Arborização Urbana - AU. Como por exemplo, o PL n 2.810/2003 (propôs alterar o EC incluindo a AU no Plano Diretor), e foi adensado ao PL $n^{\circ}$ 80/2003 (propôs alterar o EC, prevendo a realização de estudos geológicos para subsidiar o Plano Diretor); e o PL do Senado n 396/2014 (propôs a alteração do EC para dispor acerca da delimitação das áreas verdes urbanas passíveis de reflorestamento como conteúdo mínimo do Plano Diretor). Os dois PLs foram arquivados em 2008 e 2018, respectivamente. 
Já o PL no 2.897/2008, propôs incluir o inciso IV, ao Art. 42 do EC, que acrescentaria o Plano de Arborização Urbana - PDAU, estabelecendo normas sobre o plantio e a conservação de árvores nos logradouros públicos da cidade. Esse PL foi substituído pelo PL n 59/2010, "alterado pela Comissão de Meio Ambiente, Defesa do Consumidor e Fiscalização e Controle do Senado Federal, para Plano de Paisagismo Urbano" (GRISE et al., 2016, p.427).

$A$ inserção de práticas ou instrumentos de planejamento relacionados às árvores urbanas no EC, propostas pelos PLs citados, principalmente do Plano Diretor de Arborização Urbana - PDAU proporcionaria um avanço na legislação brasileira. Considerando que, a instituição de um PDAU estabelece, além do planejamento para novos plantios, um sistema permanente de manutenção das árvores de ruas, incluindo itens como: poda, controle fitossanitário, reparos de danos físicos, reposição, adubação e irrigação, se a identificação dessas necessidades for apontada no monitoramento (SCHALLENBERGER; MACHADO, 2013).

Em relação à proteção da vegetação, o Código Florestal de 2012, Lei no 12.651/2012, (BRASIL, 2012), traz uma separação entre áreas rurais e urbanas, permitindo que essas sejam protegidas e preservadas conforme suas peculiaridades, mostrando que a vegetação urbana é tão importante quanto a rural. No Art.3, inc. XX entende-se por área verde urbana:

Espaços, públicos ou privados, com predomínio de vegetação, preferencialmente nativa, natural ou recuperada, previstos no Plano Diretor, nas Leis de Zoneamento Urbano e Uso do Solo do Município, indisponíveis para construção de moradias, destinados aos propósitos de recreação, lazer, melhoria da qualidade ambiental urbana, proteção dos recursos hídricos, manutenção ou melhoria paisagística, proteção de bens e manifestações culturais; (BRASIL, 2012).

De forma simplificada, é possível perceber que as leis federais em destaque, mesmo não estando ligadas diretamente à Arborização Urbana, dispõem sobre proteção e/ou preservação dos elementos arbóreos pertencentes ao solo urbano (Quadro 1):

\begin{tabular}{|c|c|c|}
\hline REGULAMENTO & $\begin{array}{c}\text { NOME CONHECIDO DA } \\
\text { LEI }\end{array}$ & DISPÕE SOBRE \\
\hline Lei $\mathrm{n}^{\circ}$ 6.766/1979 & $\begin{array}{c}\text { Lei do Parcelamento do } \\
\text { Solo }\end{array}$ & $\begin{array}{c}\text { Parcelamento do Solo Urbano } \\
\text { (loteamentos e } \\
\text { desmembramentos) }\end{array}$ \\
\hline Lei no 6.938/1981 & $\begin{array}{c}\text { Lei Nacional de Meio } \\
\text { Ambiente }\end{array}$ & $\begin{array}{c}\text { Preservar, melhorar e recuperar } \\
\text { a qualidade ambiental }\end{array}$ \\
\hline Lei $\mathrm{n}^{\circ}$ 12.651/2012 & Código Florestal & Proteção das Florestas Nativas \\
\hline
\end{tabular}

Fonte: Brasil (1979; 1981; 2012)

Quadro 1. Leis federais referentes às questões ambientais e parcelamento do solo

Chart 1. Federal laws related to environmental issues and land parceling 
Com base na legislação federal citada foi possível perceber que as Leis, mesmo não estando ligadas diretamente à Arborização Urbana, dispõe sobre proteção e/ou preservação dos elementos arbóreos pertencentes ao solo urbano. Já os Projetos de Lei, buscaram tratar especificamente desta temática, o que proporcionaria uma maior padronização na aplicação de políticas públicas de Arborização Urbana, dando suporte aos níveis estadual e municipal.

Nota-se a importância de políticas nacionais pela preservação ambiental, embora ela seja vista de forma ampla e pouco aprofundada (CAICHE; PERES, 2019). A incorporação da Arborização Urbana na legislação e preservação nas políticas ambientais é tão importante quanto à de praças, jardins e parques públicos, cuja relevância se fundamenta na qualidade de vida da cidade, considerando que esses espaços públicos são "objeto de disciplina pelo planejamento urbano, nos termos do art. $2^{\circ}$, IV, da Lei 10.257/01" - Estatuto da Cidade (EC) (CAOP-MAHU, 2019, p. 23) e que o EC contribui com o direito às cidades sustentáveis.

\section{Arborização urbana na legislação estadual}

Alguns estados têm tomado iniciativas para incentivar que os municípios se unam para estabelecer metas de eficiência ambiental e juntos consigam melhores resultados, incluindo a Arborização Urbana em suas leis, além de outros instrumentos de planejamento como programas, projetos, etc., sendo ações pontuais a nível estadual, revelando preocupação com essa atividade.

Nessa perspectiva, o Estado de São Paulo, em 2007, lançou o Programa Município Verde Azul (PMVA) que, segundo Dantas e Passador (2019), surgiu com o intuito de promover uma agenda ambiental, no qual propôs parâmetros comuns aos municípios paulistas, gerando também um sistema de avaliação e monitoramento da gestão ambiental, certificando os melhores desempenhos. As ações propostas pelo PMVA compõem dez diretivas ambientais compostas por tarefas que norteiam as ações municipais, sendo um dos critérios, a elaboração e implantação do Plano Municipal de Arborização Urbana. Vários dos municípios de São Paulo passaram a criar seus respectivos Planos de Arborização Urbana, principalmente após o incentivo do PMVA.

Em questões de Planos de Arborização Urbana, o Estado de São Paulo possui vários municípios que tomaram essa iniciativa, provavelmente após o incentivo do PMVA, mas ainda existem municípios que utilizam manuais ou um instrumento específico, como por exemplo, cartilhas de arborização. A falta de um manual ou de um modelo específico estadual para a elaboração de Planos torna os municípios responsáveis por seus conteúdos, o que dificulta o trabalho das prefeituras que devem escolher um modelo para se basear, nem sempre contendo os requisitos fundamentais para a elaboração de um Plano Municipal aplicável. 
O município de Porto Alegre - RS foi um dos primeiros a elaborar um Plano Diretor de Arborização Urbana - PDAU, mas, como no Estado de São Paulo, não existe um manual estadual no Rio Grande do Sul que dê diretrizes aos municípios.

Por outro lado, no Estado do Paraná elaborou-se um manual com a finalidade de subsidiar os 399 municípios do Estado, norteando-os na elaboração de seus Planos Municipais de Arborização Urbana. Esse manual não é obrigatório, mas foi recomendado aos municípios pela Secretaria Estadual de Meio Ambiente e Recursos Hídricos - SEMA, por meio da Resolução SEMA n 40/2018, na qual um "Comitê de Trabalho Interinstitucional" foi constituído para, dentre outras atribuições, realizar a análise e conformidade dos Planos Municipais de Arborização Urbana no Estado (CAOP-MAHU, 2019).

Em Estados onde não há incentivos para os Planos Municipais de arborização, muitas vezes partindo da iniciativa de companhias elétricas, é comum encontrar manuais de arborização, principalmente nas capitais. Segundo Bobrowski e Biondi (2012, p. 21) "os planos diretores da arborização de ruas de cidades brasileiras e as companhias de energia elétrica em geral têm fornecido orientações sobre os procedimentos relacionados à manutenção de padrões de plantio".

No entanto, não é apenas pelo incentivo de companhias elétricas, o próprio Estatuto da Cidade, com a obrigatoriedade do Plano Diretor, dá autonomia para os municípios, independentemente da existência ou não de leis estaduais. A obrigatoriedade de elaboração do Plano Diretor atribui aos municípios a responsabilidade pelo ordenamento de seus territórios e, consequentemente, os elementos nele presentes, inclusive as árvores do solo urbano.

Em relação à legislação estadual sobre arborização e/ou o incentivo de elaboração de Planos de Arborização foram encontrados apenas seis estados brasileiros compondo algum tipo de regulação a respeito de Arborização Urbana (Quadro 2):

\begin{tabular}{|c|c|c|}
\hline ESTADO & REGULAMENTO & DISPÕE SOBRE \\
\hline Ceará & Lei no $16.002 / 2016$ & $\begin{array}{c}\text { Valorização das espécies nativas; incentivo } \\
\text { da elaboração de Planos de Arborização }\end{array}$ \\
\hline Paraíba & Lei no $7.182 / 2002$ & $\begin{array}{c}\text { Obrigação de arborização de prédios em } \\
\text { construção }\end{array}$ \\
\hline Paraná & Lei Ordinária no $10.066 / 1992$ & $\begin{array}{c}\text { Criação da Secretaria do Meio Ambiente } \\
\text { (SEMA); incentivo à implantação de bosques, } \\
\text { hortos e arborização urbana }\end{array}$ \\
\hline
\end{tabular}




\begin{tabular}{|c|c|c|}
\hline Piauí & Decreto n 16.616/2016 & $\begin{array}{c}\text { Dispõe sobre as normas de Arborização } \\
\text { Urbana no âmbito dos municípios do Estado } \\
\text { do Piauí }\end{array}$ \\
\hline $\begin{array}{c}\text { Santa } \\
\text { Catarina }\end{array}$ & Lei $\mathrm{n}^{\circ} 17.113 / 2017$ & $\begin{array}{c}\text { Utilização de mudas de plantas nativas da } \\
\text { flora catarinense }\end{array}$ \\
\hline São Paulo & Lei no 13.580/2009 & $\begin{array}{c}\text { Programa Permanente de Ampliação das } \\
\text { Areas Verdes Arborizadas Urbanas }\end{array}$ \\
\hline
\end{tabular}

Fonte: Ceará (2016); Paraíba (2002); Paraná (1992); Piauí (2016); Santa Catarina (2017) e

Quadro 2. Regulação estadual sobre arborização urbana

São Paulo (2009).

Chart 2. State regulation of afforestation

\section{Arborização urbana na legislação municipal}

O Plano Diretor, exigido desde a Constituição Federal de 1988 e regulamentado pelo Estatuto da Cidade, engloba o planejamento territorial, portanto, é recomendável que tenha um enfoque ambiental, pois, dentre os instrumentos de planejamento urbano, conforme Brasil (2001), ele é um instrumento básico da política de desenvolvimento e expansão urbana, parte integrante do processo de planejamento municipal e, tem o objetivo de ordenar a cidade, de modo que, a propriedade urbana cumpra sua função social "assegurando o atendimento das necessidades dos cidadãos quanto à qualidade de vida, à justiça social e ao desenvolvimento das atividades econômicas".

Nesse sentido, além do Plano Diretor que abrange todo o território, para facilitar a organização por setores, os municípios podem elaborar Planos Diretores setoriais voltados para diferentes temáticas voltadas ao ordenamento territorial, como Planos Diretores de: Gestão das Águas, Resíduos Sólidos, Qualidade do Ar, etc., inclusive o Plano Diretor de Arborização Urbana.

Em questões de nomenclatura, algumas prefeituras utilizam o nome "Plano Diretor de Arborização Urbana", outras "Plano Municipal de Arborização Urbana" e outras tratam da Arborização Urbana com outros instrumentos de planejamento. É importante enfatizar que aos municípios não basta apenas a preocupação com a introdução de árvores no meio urbano, mas a manutenção dos indivíduos arbóreos já existentes, cuidando para maximizar os benefícios e minimizar os conflitos que podem ocorrer com a infraestrutura urbana.

O Plano Diretor de Arborização Urbana - PDAU de Porto Alegre, um dos primeiros elaborados no Brasil, foi realizado a partir de inventários preliminares feitos no município e traçou diretrizes de planejamento, implantação, conservação e administração das árvores públicas, de forma que as demandas técnicas e as manifestações de interesse das comunidades locais fossem atendidas. Não foram encontrados registros que permitissem afirmar se esse PDAU foi 
o exemplo inicial para outras cidades ou para o próprio Projeto de Lei $n^{0}$ 2.897/2008, porém, como Porto Alegre, alguns municípios passaram a elaborar seus PDAUs de diversas formas, desde Decretos Municipais, Leis Complementares, até Planos Municipais.

Cumprindo a obrigatoriedade na legislação federal, um conjunto de municípios elaborou seus Planos Diretores, porém, ainda não são muitos os que elaboraram Planos Municipais de Arborização, sendo que alguns estão durante esse processo. "O Plano Diretor de Arborização Urbana - PDAU deve ser um documento elaborado, discutido e aprovado pelo município, levando em consideração a participação popular, complementando o Plano Diretor do Município (...)" (SCHALLENBERGER; MACHADO, 2013).

Os Planos Diretores de Arborização Urbana ainda não são obrigatórios nos municípios brasileiros. Os municípios abrangidos pelos estados do Paraná e São Paulo, que obtém um manual e um programa estadual, respectivamente, têm sido impulsionados a essa prática pela regulação estadual, porém, mesmo nos outros estados que também possuem alguma base legal sobre arborização (Ceará - CE, Paraíba - PB, Piauí - PI, Santa Catarina - SC), não há uma padronização na regulação sobre o tema.

No levantamento, foi possível identificar diferentes tipos de instrumentos normativos para a Arborização em municípios desses estados, como por exemplo, Plano de Arborização Urbana (Sobral - CE; João Pessoa - PB; Teresina - PI); Manual de Arborização Urbana (Fortaleza - CE); Inserção da Arborização Urbana no Plano Diretor (Criciúma - SC). Essa busca foi realizada para exemplificar a divergência entre instrumentos sobre Arborização Urbana mesmo nos estados com regulações sobre essa temática, em municípios de outros estados, se fosse viável uma busca completa, provavelmente se encontrariam muito mais divergências.

Considerando a carência de legislação federal e estadual relacionada à temática da Arborização Urbana, os municípios brasileiros não têm um dispositivo legal que lhes dê suporte nesse sentido, dependendo de Programas ou Manuais estaduais, quando existentes, ou até mesmo dos manuais de companhias elétricas como já citado. No caso da elaboração dos PDAUs, a falta de um modelo específico estadual para a elaboração de Planos, como a iniciativa do Estado do Paraná, torna os municípios responsáveis por seus conteúdos, o que dificulta o trabalho das Prefeituras que nem sempre conhecem os requisitos fundamentais para a elaboração de um Plano adequado, podendo acarretar deficiências no planejamento da Arborização Urbana local, o que reflete no planejamento da arborização urbana de todo o país. 


\section{CONCLUSÕES}

No Brasil, existem algumas leis fundamentais, na legislação federal, relacionadas às questões ambientais e do parcelamento do solo urbano que delimitam ações relativas ao meio ambiente e ao ordenamento do território, porém, não há instituída uma Politica Nacional de Arborização Urbana. Houve a iniciativa de alguns Projetos de Lei - PLs que propuseram alterações no Estatuto da Cidade - EC, tentando incorporar nele a Arborização Urbana. Entretanto, nenhum desses PLs foi instituído como Lei até o momento.

Dessa forma, percebe-se uma carência quanto às leis federais, municipais e estaduais capazes de orientar e regulamentar a prática da Arborização Urbana.

Os Estados brasileiros, mesmo com a carência de leis federais, têm tomado a iniciativa de incorporar a Arborização Urbana em suas leis ou outros instrumentos de planejamento como programas, projetos, manuais, etc., mas em apenas seis deles, foram encontradas leis que regulamentem a prática de Arborização Urbana: Ceará, Paraíba, Piauí, Paraná, Santa Catarina e São Paulo.

Grande parte da responsabilidade em relação à Arborização Urbana ainda é depositada nos municípios, responsáveis pela elaboração de seus planos diretores e, consequentemente, pelo seu ordenamento territorial. Entretanto, a falta de informações em bases de dados nacional como, por exemplo, no IBGE dificultou o levantamento dos dados no nível municipal.

Constatou-se que, devido a carência de legislação federal e estadual relacionada sobre Arborização Urbana, os municípios brasileiros não têm um suporte legal específico nessa temática, ficando dependentes de Programas ou Manuais estaduais, quando existentes, ou até mesmo dos manuais de companhias elétricas.

A falta de um modelo estadual para a elaboração de Planos de Arborização Urbana, como a iniciativa do Estado do Paraná, dificulta a padronização de normas para a implantação da Arborização Urbana em nível local, refletindo no planejamento da arborização urbana de todo o país.

Concluiu - se que, a incorporação da exigência da elaboração de Planos Diretores de Arborização Urbana - PDAUs na legislação brasileira, atrelada à criação de uma Política Nacional de Arborização Urbana, com seus devidos instrumentos e sistemas de gestão, poderia conduzir a uma maior padronização na aplicação de políticas públicas de Arborização Urbana nos municípios e contribuir com o direito às cidades sustentáveis previsto no Estatuto da Cidade - Lei Federal n 10.257/2001. 


\section{AGRADECIMENTOS}

Agradecemos à Coordenação de Aperfeiçoamento de Pessoal de Nível Superior - Brasil (CAPES) - Código Financeiro 001, pelo suporte financeiro para a realização deste trabalho e à Universidade Federal de São Carlos - UFSCar.

\section{REFERÊNCIAS}

AHERN, J. From Fail-safe to Safe-to-fail: Sustainability and Resilience in the New Urban World. Landscape and urban Planning, Netherlands, v. 100, n. 4, p. 341-343, 2011.

ANDRADE, C. C.; HOLANDA, A. Apontamentos sobre pesquisa qualitativa e pesquisa empírico-fenomenológica. Estudos de Psicologia, Campinas, v. 27, n. 2, p. 259-268, 2010.

BENINI, S. M.; MARTIN, E. S. Decifrando as Áreas Verdes Públicas. Revista Formação (online), Presidente Prudente, v. 2, n. 17, p. 63-80, 2010.

BERNARDY, R. J. O Planejamento Urbano de Pequenos Municípios com Base no Plano Diretor. Desenvolvimento em Questão, ljuí, v. 11, n. 22, p. 4-34, 2013.

BOBROWSKI, R.; BIONDI, D. Caracterização do padrão de plantio adotado na arborização de ruas de Curitiba, Paraná. Revista da Sociedade Brasileira de Arborização Urbana, Piracicaba, v. 7, n. 3, p. 20-30, 2012.

BRANCALION, P. H. S.; GARCIA, L. C.; LOYOLA, R.; RODRIGUES, R. R.; PILLAR, V. D.; LEWINSOHN, T. M. Análise crítica da Lei de Proteção da Vegetação Nativa (2012), que substituiu o antigo Código Florestal: atualizações e ações em curso. Natureza \& Conservação, Rio de Janeiro, v. 14, n. 1, p. e1-e16, 2016.

BRASIL. Lei no 6.766, de 19 de dezembro de 1979. Dispõe sobre o Parcelamento do Solo Urbano e dá outras Providências. Brasília, 1979. Disponível em: <http://www.planalto.gov.br/ccivil_03/leis//6766.htm>. Acesso em: 09 dez. 2019.

BRASIL. Lei no 6.938, de 31 de agosto de 1981. Dispõe sobre a Política Nacional do Meio Ambiente, seus fins e mecanismos de formulação e aplicação, e dá outras providências. Brasília, 1981. Disponível em: <http://www.planalto.gov.br/ccivil_03/LEIS/L6938.htm>. Acesso em: 09 dez. 2019.

BRASIL. Constituição da República Federativa do Brasil de 1988, de 05 de outubro de 1988. Brasília, 1988. Disponível em: <http://www.planalto.gov.br/ccivil 03/constituicao/ constituicao.htm>. Acesso em: 09 dez. 2019.

BRASIL. Lei no 10.257, de 10 de julho de 2001, (Estatuto da Cidade) que Regulamenta os arts. 182 e 183 da Constituição Federal e estabelece diretrizes gerais da política urbana e dá outras providências. Brasília, 2001. Disponível em: <http://www.planalto.gov.br/ccivil_03/leis/leis_2001 /l10257.htm >. Acesso em: 09 dez. 2019.

BRASIL. Lei no 12.651, de 25 de maio de 2012. Dispõe sobre a proteção da vegetação nativa. Brasília, 2012. Disponível em: <http://www.planalto.gov.br/ccivil 03/_ato20112014/2012/lei/ 112651.htm>. Acesso em: 09 dez. 2019. 
CAICHE, D. T; PERES, R. B. Avances y límites de la regulación de los bosques urbanos en ciudades brasileñas: por una política nacional de bosques urbanos. In: FORUM LATINOAMERICANO DE FLORESTAS URBANAS, 2., 2019. Bogotá. Anais... Bogotá: Universidade Javierana, 2019. P. 316.

CEARÁ. Lei no $\mathbf{1 6 . 0 0 2}$, de 02 de maio de 2016. Cria o programa de valorização das espécies vegetais nativas. Ceará, 2016. Disponível em: <https://www.legisweb.com.br/legislacao/?id= 320056>. Acesso em: 09 dez. 2019.

CENTRO DE APOIO OPERACIONAL DAS PROMOTORIAS DE JUSTIÇA DE PROTEÇÃO AO MEIO AMBIENTE E DE HABITAÇÃO E URBANISMO (CAOP-MAHU). Nota técnica no 01/2019, de 08 de julho de 2019. Curitiba, 2019. Disponível em: <http://www.urbanismo.mppr. mp.br/arquivos/File/NT012019ARBO.pdf> Acesso em 03 abr. 2020.

COUTTS, A. M.; WHITE, E. C.; TAPPER, N. J.; BERINGER, J.; LIVESLEY, S. J. Temperature and human thermal comfort effects of street trees across three contrasting street canyon environments. Theoretical and applied climatology, Viena, v. 124, n. 1-2, p. 55-68, 2016.

DANTAS, M. K.; PASSADOR, C. S. A Gestão Ambiental nos Municípios do Estado de São Paulo: uma análise sob a ótica da política pública "Programa Município Verdeazul". Gestão \& Regionalidade, São Caetano do Sul, v. 35, n. 103, p.120-139, 2019.

GRISE, M. M.; BIONDI, D.; ARAKI, H. A floresta urbana da cidade de Curitiba-PR. Floresta, Curitiba, v. 46, n. 4, p. 425-438, 2016.

KRAMER, J. A.; KRUPEK, R. A. Caracterização florística e ecológica da arborização de praças públicas do município de Guarapuava, PR. Revista Árvore, Viçosa, v. 36, n. 4, p.647-658, 2012.

MULLANEY, J.; LUCKE, T.; TRUEMAN, S. J. A review of benefits and challenges in growing street trees in paved urban environments. Landscape and Urban Planning, Netherlands, v. 134, p. 157-166, 2015.

PARAÍBA. Lei no 7.182, de 12 de dezembro de 2002. Institui a obrigação de arborização de prédios em construção no âmbito do Estado da Paraíba e dá outras providências. Paraíba, 2002. Disponível em: <http://sapl.al.pb.leg.br/sapl/sapl_documentos/norma_juridica/6984_ texto_integral >. Acesso em: 09 dez. 2019.

PARANÁ. Lei Ordinária no 10.066, de 27 de julho de 1992. Cria a secretaria de Estado do meio ambiente - SEMA, a entidade autárquica instituto ambiental do Paraná - IAP e adota outras providências. Paraná, 1992. Disponível em: <https://leisestaduais.com.br/pr/lei-ordinarian-10066-1992-parana-cria-a-secretaria-de-estado-do-meio-ambiente-sema-a-entidadeautarquica-instituto-ambiental-do-parana-iap-e-adota-outras-providencias>. Acesso em: 09 dez. 2019.

PIAUÍ. Decreto no 16.616, de 09 de junho de 2016. Dispõe sobre as Normas de Arborização Urbana no âmbito do Estado do Piauí e dá outras providências. Diário Oficial do Estado do Piauí, 2016. Disponível em: <https://sogi8.sogi.com.br/Arquivo/Modulo113.MRID109/Registro 1241760/decreto\%20n\%C2\%BA\%2016.616,\%20de\%2009-06-2016.pdf>. Acesso em: 09 dez. 2019.

SANTA CATARINA. Lei no $\mathbf{1 7 . 1 1 3}$, de 24 de abril de 2017. Dispõe sobre a utilização de mudas de plantas nativas da flora catarinense nos projetos de arborização dos próprios públicos. Santa Catarina, 2017. Disponível em: <https://leisestaduais.com.br/sc/lei-ordinaria-n-17113- 
2017-santa-catarina-dispoe-sobre-a-utilizacao-de-mudas-de-plantas-nativas-da-floracatarinense-nos-projetos-de-arborizacao-dos-proprios-publicos>. Acesso em: 09 dez. 2019.

SÃO PAULO. Lei no 13.580, de 24 de julho de 2009. Institui o programa permanente de ampliação das áreas verdes arborizadas urbanas, e dá outras providências. São Paulo, 2009. Disponível em: <https://www.al.sp.gov.br/repositorio/legislacao/lei/2009/lei-1358024.07.2009.html>. Acesso em: 09 dez. 2019.

SCHALLENBERGER, L. S.; MACHADO, G.O. Inventário da Arborização na Região Central do Município de Mangueirinha - PR. Revista da Sociedade Brasileira de Arborização Urbana, Piracicaba, v. 8, n. 1, p. 54-64, 2013. 